\title{
Gamificação na Educação: aplicação de elementos de jogos no Módulo de Tabela Verdade que auxilia no processo de ensino- aprendizagem da disciplina de Lógica
}

\author{
Fernanda Pereira Gomes ${ }^{1}$, Parcilene Fernandes de Brito ${ }^{1}$ \\ ${ }^{1}$ Departamento de Computação - Centro Universitário Luterano de Palmas (CEULP/ULBRA) \\ Avenida Teotônio Segurado, CEP 77.019-900 - Palmas - TO - Brasil \\ \{fernandagomes769, parcilene\} @gmail.com
}

\begin{abstract}
Resumo. A gamificação pode ser caracterizada como o uso de elementos e mecanismos de jogos que objetivam estimular comportamentos e despertar engajamento entre um público especifico. Os cenários em que a gamificação pode ser aplicada vão desde setores financeiros, saúde e educação, e neste último, é capaz de proporcionar experiências de aprendizado customizadas a partir das necessidades dos alunos. Nesse sentido, o presente trabalho apresenta os conceitos, teorias e técnicas da gamificação centrada no contexto educacional, e uma proposta de gamificação do Módulo de Tabela Verdade desenvolvido para o projeto Logic Live, uma plataforma online para auxílio ao processo de ensino-aprendizagem da disciplina de Lógica.
\end{abstract}

\section{Introdução}

Nos últimos anos, um conjunto de elementos de design de jogos são aplicados em diversas áreas como saúde, gestão de negócios e educação para despertar engajamento entre públicos específicos (VIANNA et al., 2013). Para esse conjunto de elementos, definiu-se o termo "gamificação" (do original em inglês gamification), que consiste no uso de mecânicas e dinâmicas de jogos em contextos de "não-jogos", ou seja, atividades que comumente não possuem propósitos de entretenimento.

Sabendo que o uso dos conceitos e técnicas de gamificação são úteis para o aprendizado, estimulando a participação dos alunos nas atividades educativas, o trabalho apresenta uma proposta de gamificação do Módulo de Tabela Verdade desenvolvido que será integrado à plataforma do projeto Logic Live, vinculado ao Grupo de Estudos em Novas Tecnologias para processos de Ensino e Aprendizagem (GENTE) do CEULP/ULBRA.

Tal plataforma tem como objetivo auxiliar no processo de ensino-aprendizagem da disciplina de Lógica, e o Módulo de Tabela Verdade, em especial, aborda parte dos conteúdos ministrados nessa disciplina. Especificamente, são apresentados assuntos referentes à validação das fórmulas da Lógica Proposicional, seguindo o método de Tabela Verdade, que analisa e apresenta o passo a passo das verificações de cada possibilidade de valores verdades para as fórmulas.

\section{Gamificação}

Conforme Hagglund (2012), o termo Gamificação foi citado pela primeira vez em 2002 pelo programador de jogos Nick Pelling, quando este teve a ideia de auxiliar empresas a desenvolver novos produtos através de plataformas de entretenimento. Devido à falta de interesse na ideia, o autor aponta que o termo não recebeu a devida atenção no campo empresarial, e ganhou popularidade somente anos depois, quando segmentos da indústria de jogos passaram a usar o termo.

Desde então, algumas definições foram vinculadas ao termo, mas Deterding et al. (2011) formularam inicialmente o conceito de Gamificação como "o uso de elementos de design de jogos em contextos de não-jogos". Com a expansão do termo, diversos produtos 
gamificados foram desenvolvidos no âmbito comercial, e até mesmo eventos científicos passaram a apresentar estudos envolvendo a gamificação, de modo que um crescente espaço foi sendo ocupado e suas aplicações foram aumentando.

Segundo Vianna et al. (2013), a Gamificação caracteriza-se por introduzir elementos de jogos em atividades não lúdicas e em contextos que não envolvem o entretenimento, visando um maior engajamento de pessoas com tais atividades. Nos últimos anos, mecanismos de jogos têm sido aplicados em campos variados, especificamente, na educação, saúde, corporações e até mesmo em políticas públicas, tornando agradáveis tarefas consideradas tediosas e dando algum tipo de ludicidade ou competitividade a elas.

Para Azarite (2013), qualquer proposta que aponte para circunstâncias que envolvam caráter lúdico ou de desafio, criação ou adaptação da experiência do usuário a determinado produto, serviço ou processo, pode ser considerada como uma ação gamificada. Segundo Menezes et al. (2014), a gamificação mostra-se como uma estratégia válida para despertar emoções positivas, explorar aptidões pessoais ou atrelar recompensas virtuais ou físicas ao cumprimento de tarefas.

\subsection{Elementos de Jogos}

Conforme Bunchball (2010), o objetivo da Gamificação é fazer com que as pessoas participem e interajam mais ativamente de atividades de "não-jogos". Mas, para isso, deve haver a aplicação de mecânica e dinâmica de jogos na atividade em questão, que são os elementos necessários para tornar a gamificação uma estratégia capaz de influenciar e até mesmo direcionar o comportamento das pessoas.

A mecânica de jogo consiste nas regras e recompensas que compõem o jogo, ou seja, os aspectos que o torna desafiador, divertido e satisfatório; já a dinâmica de jogo são as emoções, ou o resultado do sentimento de desejos e motivações (BUNCHBALL, 2010). A adição de elementos de mecânica de jogos em sistemas ou aplicações web, individualmente ou em conjunto, criam experiências atraentes capazes de motivar os usuários.

Conforme Hagglund (2012), as mecânicas e dinâmicas possuem significados e atribuições diferentes, e para que um jogo seja bem sucedido, precisam ser bem definidas e ajustadas para alcançar mais jogadores ao longo do tempo e manter as atividades cada vez mais atraentes. Werbach e Hunter (2012) definem três elementos fundamentais aos estudos e desenvolvimento da gamificação, que são: dinâmicas, mecânicas e componentes. Tais elementos formam uma tríade organizada em ordem decrescente de abstração de modo que cada mecânica pode relacionar-se a uma ou mais dinâmicas, e cada componente a uma ou mais mecânicas ou dinâmicas, como mostra a Figura 1. Neste modelo, as Dinâmicas são o nível mais alto de abstração, as Mecânicas vem em segundo nível e os Componentes em terceiro.
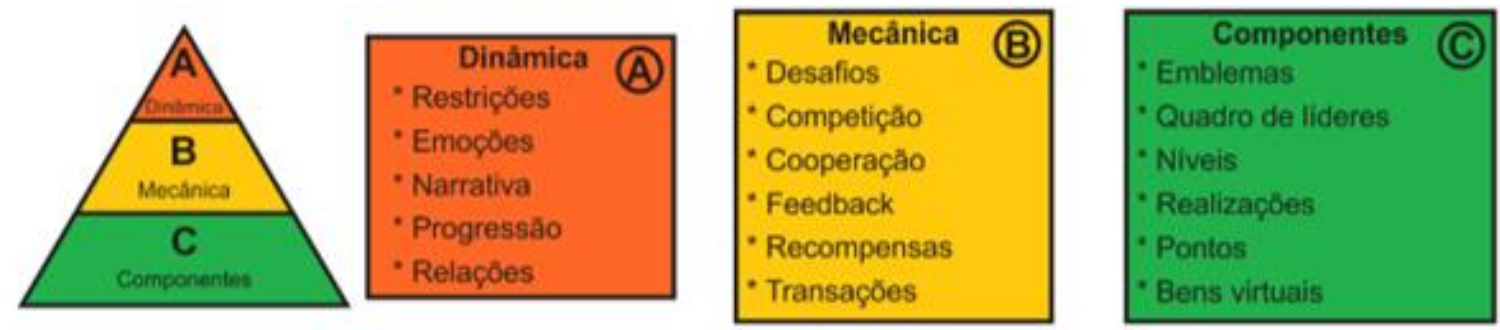

Figura 1 - Pirâmide da hierarquia dos elementos dos jogos

A Figura 1 apresenta a pirâmide da hierarquia dos elementos dos jogos. Para Werbach e Hunter (2012), o design de um jogo deve começar do mais alto nível de abstração, ou seja, é necessário decidir quais são os principais elementos das dinâmicas que o jogo irá abordar, que podem ser Restrições, Emoções, Narrativa, Progressão e Relações. Depois disso, é sugerido que a mecânica seja definida com base nos seguintes elementos: Desafios, Competição, Cooperação, Feedback, Recompensas e Transações. 
A escolha dos elementos da mecânica deve se alinhar aos elementos da dinâmica escolhidos anteriormente, de forma que se encaixem melhor no conceito do jogo que será proposto. Finalmente, poderão ser definidos os componentes que farão parte do design, e estes podem ser: Emblemas, Quadro de líderes, Níveis, Realizações, Pontos e Bens Virtuais. Os componentes são aplicações específicas visualizadas e utilizadas na interface do jogo, e é o nível mais concreto dos elementos de jogos.

\section{Gamificação na Educação}

A Gamificação propõe tornar atividades comuns em situações mais atraentes e motivadoras, adicionando elementos e mecanismos de jogos a elas. Nesse sentido, a gamificação tem sido utilizada em contextos variados e, conforme Oliveira e Monteiro (2016), pesquisas realizadas indicam que a aplicação de gamificação na educação é capaz de estimular comportamentos de alunos, proporcionando um maior engajamento destes em sala de aula, tornando as atividades mais divertidas e com melhores resultados.

Pensar em Gamificação na educação é pensar em uma proposta que contemple alguns aspectos de ludicidade, mecanismos de jogos, com uma abordagem desafiadora a fim de aumentar o engajamento dos alunos nos processos educacionais, por meio de um ambiente motivador e divertido (MENEZES et al., 2014). Conforme Medeiros e Haydu (2015), os ambientes formais de ensino apresentam algumas semelhanças com os jogos, seja na atribuição de pontos para tarefas e/ou trabalhos realizadas ou na oferta de níveis de experiências diferentes por ter alcançado uma meta específica.

No entanto, são apresentadas dificuldades ao tentar manter o engajamento dos alunos e principalmente fazer com que estes se interessem pelas atividades em sala de aula. Para isso, deve-se compreender a função da Gamificação na Educação, e então identificar as situações em que os elementos de jogos contribuem de fato para difusão de comportamentos úteis ao aprendizado (MEDEIROS; HAYDU, 2015). Pesquisas apontam que estudantes sujeitos ao ensino com jogos apresentam melhores níveis de compreensão dos conteúdos abordados nas disciplinas, motivação e engajamento (OLIVEIRA; MONTEIRO, 2016).

\section{Módulo de Tabela Verdade}

Conforme Gomes e Brito (2018), para o desenvolvimento do Módulo de Tabela Verdade foi necessário inicialmente aprofundar conhecimentos relacionados à Lógica, como também, identificar a abordagem utilizada por professores dos cursos na área de Computação, que ministram os conteúdos dessa disciplina. Com isso, foi possível estabelecer sua estrutura, composta pelos módulos A, B e C, como mostra a Figura 2. 


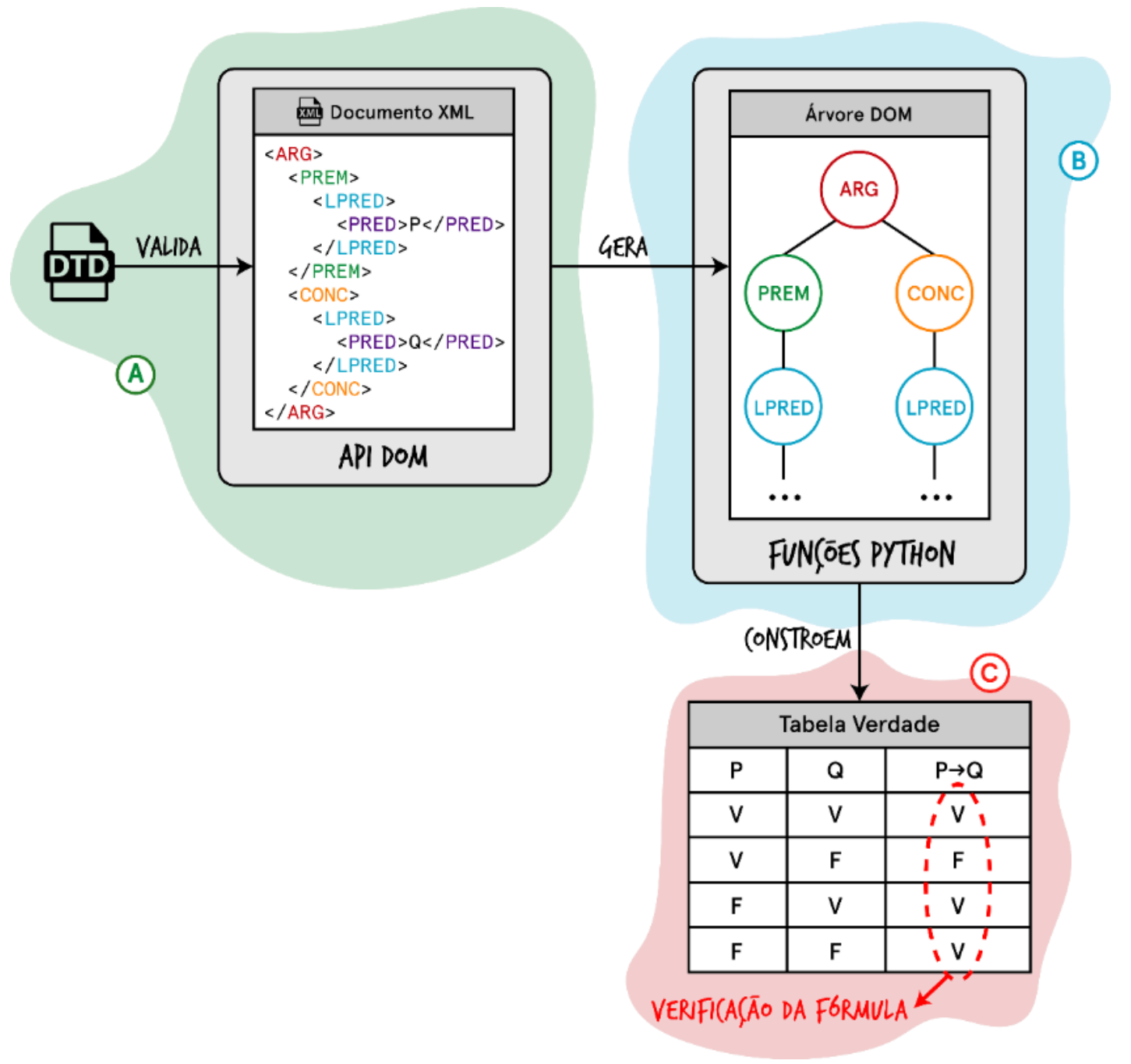

Figura 2 - Estrutura do Módulo de Tabela Verdade

A Figura 2 apresenta a estrutura definida para o módulo de Tabela Verdade. Segundo Gomes e Brito (2018), em sua composição, na Figura 2-A, o DTD representado corresponde ao documento responsável por especificar os elementos a serem empregados nos documentos XML, e o conjunto de regras a serem verificadas para então validá-lo. Os documentos XML contém os elementos da fórmula da Lógica Proposicional, escritos através de um editor de texto ou de uma ferramenta própria para trabalhar com documentos XML.

Após a inserção dos elementos no documento XML, é executada a validação do mesmo através do DTD, e este sendo considerado válido dentre as especificações, é analisado no ambiente de programação Python, a partir da utilização do parser contido na API DOM, que gera logo em seguida, uma árvore na memória como forma de representação do documento, como mostra a Figura 2-B.

Os elementos da árvore gerada são manipulados através de um conjunto de funções desenvolvidas utilizando a linguagem de programação Python, que utilizam métodos existentes na API DOM, capazes de identificar a estrutura e o conteúdo disposto na memória (Figura 2-B). As funções Python implementadas são responsáveis também por construir a tabela verdade correspondente à fórmula, e então realizar sua verificação (Figura 2-C). Por fim, para apresentação da tabela gerada, foi criado um template em HTML (Hypertext Markup Language), de modo simplificado, que permitisse a interação do usuário através de uma tela simples e objetiva, conforme apresentado na Figura 3. 


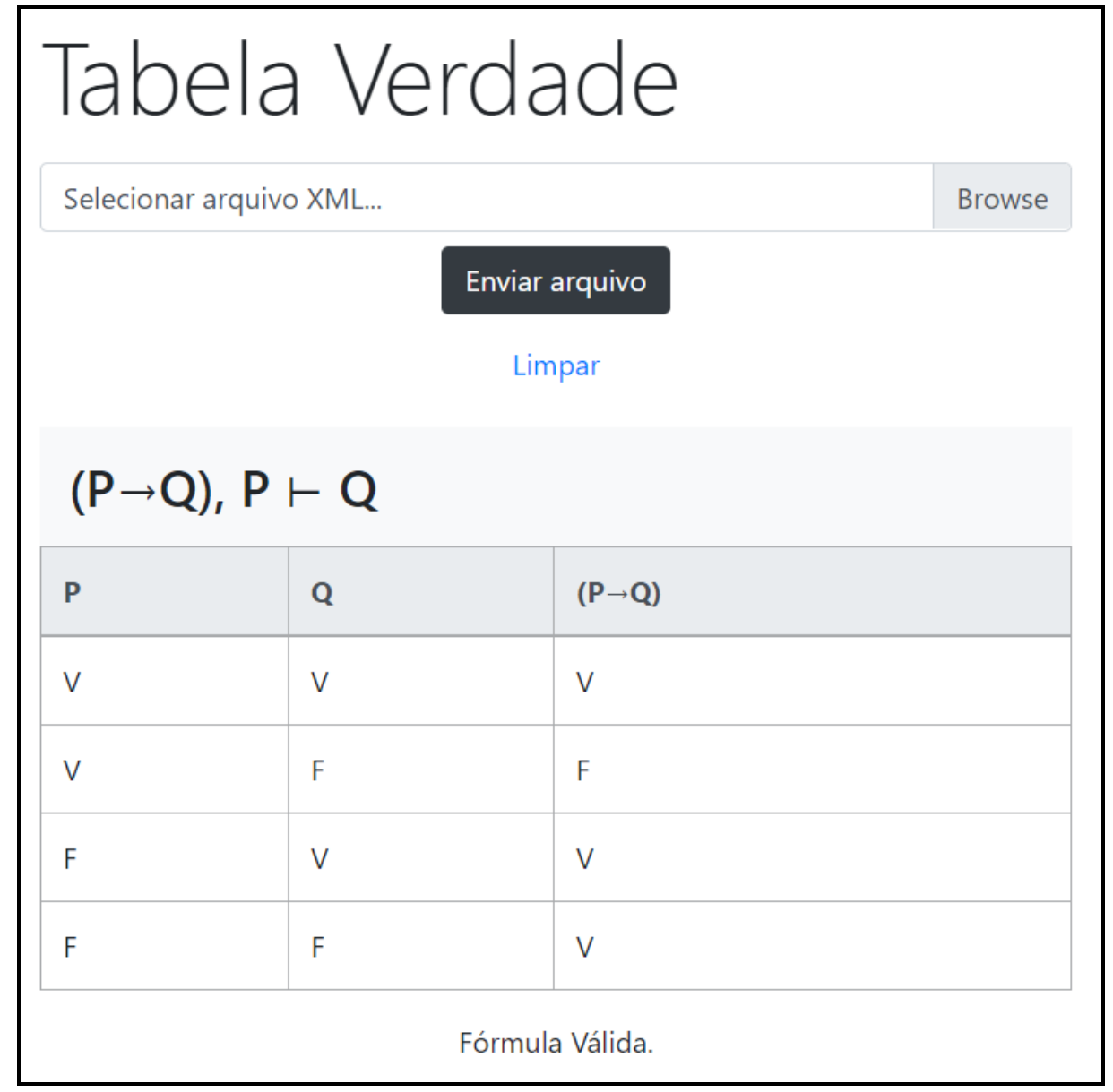

Figura 3 - Tela do módulo para exibição da tabela verdade correspondente a uma fórmula

A Figura 3 apresenta a tela do Módulo de Tabela Verdade desenvolvido após ser gerada a tabela verdade correspondente a uma fórmula da lógica proposicional. Primeiramente, é apresentada a fórmula completa, logo em seguida, é exibida a tabela verdade resultante para a fórmula, de modo que seu passo-a-passo possa ser analisado pelo usuário. Abaixo da tabela verdade, é apresentado o resultado correspondente do tipo de verificação da fórmula em questão.

Caso a fórmula não possua premissas, será verificada a conclusão da fórmula como um todo, e apresentado o resultado da verificação, indicando que a mesma é Tautológica, ou Inconsistente ou Contingente. Já para fórmulas que possuem premissas, será verificado se as formas de argumento são válidas ou inválidas. Vale ressaltar que os resultados apresentados pelo módulo contribuem na compreensão e avaliação da fórmula proposicional por parte do usuário, a partir da construção automática de tabelas verdade para fórmulas da Lógica Proposicional.

\section{Materiais e Métodos}

Para o desenvolvimento da proposta de gamificação do Módulo de Tabela Verdade desenvolvido (seção 4), as etapas representadas na Figura 4 foram seguidas. Na etapa "Revisão Literária", ocorreu o estudo referentes às teorias e técnicas da gamificação, como também assuntos relacionados à disciplina de Lógica, os conceitos da Lógica Proposicional, e as definições do método de tabela verdade.

Em seguida, na etapa "Estudo da Metodologia" (Figura 4), realizou-se o estudo da metodologia de ensino utilizada pela professora Parcilene Fernandes de Brito no Centro Universitário Luterano de Palmas - CEULP/ULBRA. Em reuniões ocorridas com a mesma, foi possível obter conhecimento sobre a forma de ensino do método de Tabela Verdade para 
os acadêmicos em sala de aula (na disciplina de Lógica de Predicados), e como esse método é aplicado para a verificação da fórmula e da validade das formas de argumento.

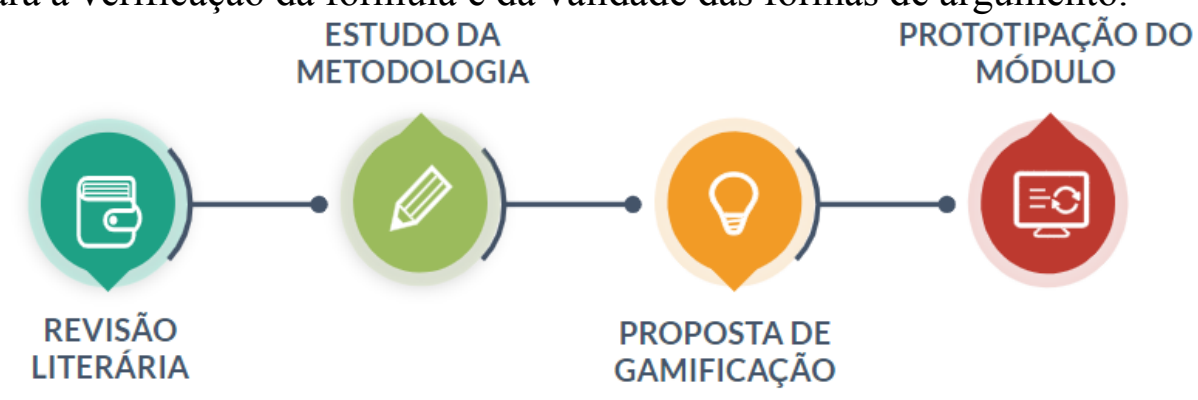

Figura 4 - Processo das etapas desenvolvidas no trabalho

A Figura 4 representa as etapas que foram realizadas para o desenvolvimento do trabalho. A etapa "Proposta de Gamificação" consistiu na definição dos possíveis comportamentos que serão estimulados nos usuários ao utilizarem o Módulo gamificado, como por exemplo, o estímulo para realizar atividades no sistema, responder exercícios, acessar com mais frequência o sistema, entre outros.

Além disso, realizou-se o estudo dos elementos e mecanismos de jogos que fossem capazes de estimular comportamentos dos usuários, e estudo dos recursos e técnicas computacionais que permitiriam a integração desse elementos no Módulo. Por fim na etapa "Prototipação do Módulo", a partir de reuniões com a especialista do domínio (professora da disciplina), foram definidas as características da nova interface do Módulo de Tabela Verdade, capaz de suportar os elementos da gamificação estabelecidos na etapa anterior. Como resultados desta etapa, têm-se os protótipos das telas do módulo gamificado, capazes de auxiliar na implementação da gamificação.

\section{Resultados}

Para a proposta de gamificação, foi definida uma nova estrutura do Módulo de Tabela Verdade. Juntamente com a especialista do domínio, o módulo passa a apresentar conceitos básicos abordados na disciplina, de modo que o usuário efetue inicialmente o estudo desses conceitos antes de realizar qualquer atividade.

Para constituir um conjunto de exercícios que abrangem os conteúdos apresentados, níveis de dificuldade foram definidos para os agruparem. Com nível de dificuldade considerado iniciante, intermediário, e avançado, cada exercício possui uma fórmula da Lógica Proposicional diferente para ser estudada.

Baseando-se nessa estrutura, foram definidos os elementos e mecanismos de jogos para compor a gamificação do Módulo. Conforme os elementos identificados nos trabalhos encontrados na etapa de revisão (Figura 5), foram definidas as seguintes dinâmicas de jogos:

- Progressão: para estimular o engajamento do usuário-aprendiz nas atividade de estudo, este poderá acompanhar no Módulo sua evolução no cumprimento das atividades propostas, através feedback adequado e apresentação dos resultados de sua interação;

- Restrição: para motivar o usuário-aprendiz a atingir os objetivos propostos no Módulo, este terá que cumprir as regras definidas no Módulo.

A partir das dinâmicas definidas, iniciou-se o detalhamento das mecânicas. Definiu-se o uso da mecânica de desafios, pois esta contribuirá para que o usuário perceba que está progredindo, já que só poderão ser realizados os desafios propostos somente quando o usuário finalizar todos os exercícios de um nível (regra estabelecida). Para o fortalecimento das regras, também foi considerada a mecânica de recompensas, que foram definidas com base nos possíveis comportamentos que serão realizados pelos usuários.

Após as mecânicas serem estabelecidas, estas auxiliaram na escolha dos elementos de jogos mais específicos e concretos para a implementação, que são: avatar, emblemas, níveis, 
pontos e tabela de classificação. A partir disso, foi feita a interligação das recompensas com os elementos de jogos definidos, conforme a dificuldade de realização e a importância do comportamento para o processo de aprendizagem no Módulo, como mostra a Tabela 1 a seguir.

Tabela 1 - Definição das recompensas por comportamento

\begin{tabular}{c|c}
\hline Comportamento & Recompensas \\
\hline $\begin{array}{c}\text { Concluir exercício de estudo dos conceitos } \\
\text { da Lógica de Predicados }\end{array}$ & 40 pontos + Emblema \\
\hline $\begin{array}{c}\text { Acertar exercício de criação de tabela } \\
\text { verdade e identificação de fórmulas }\end{array}$ & 50 pontos \\
\hline $\begin{array}{c}\text { Acertar exercício de verificação da validade } \\
\text { de formas de argumento }\end{array}$ & 80 pontos \\
\hline $\begin{array}{c}\text { Concluir um nível Iniciante ou Intermediário } \\
\text { Concluir um nível Avançado }\end{array}$ & 100 pontos \\
\hline Acertar um Desafio & 120 pontos + Emblema \\
\hline
\end{tabular}

A Tabela 1 apresenta as recompensas definidas por comportamento. Com base nas definições, concluir um exercício de estudo dos conceitos beneficiará o usuário com 40 pontos mais um emblema personalizado, no entanto, concluir um nível Iniciante ou Intermediário o beneficiará com o dobro de pontos, pois completar um nível de exercícios requer mais interação do que estudar os conceitos.

Como se deseja reforçar o processo de ensino-aprendizagem, as maiores recompensas serão dadas somente quando o usuário concluir um nível Avançado (envolve exercícios com um grau maior de dificuldade) ou acertar um Desafio. O avatar é uma exceção, não dependendo de recompensas para existir, pois é importante para possibilitar uma identidade ao usuário no Módulo.

Já a tabela de classificação é interligada com os pontos recebidos por recompensa, nela serão apresentados os cinco primeiros classificados (os que mais pontuarem), e posteriormente a pontuação do usuário logado. Após a definição dos elementos e mecanismos de jogos, foi realizada a prototipação das telas da aplicação sob orientação da especialista do domínio. A Figura 5 mostra o protótipo que representa a tela inicial do Módulo de Tabela Verdade gamificado. 


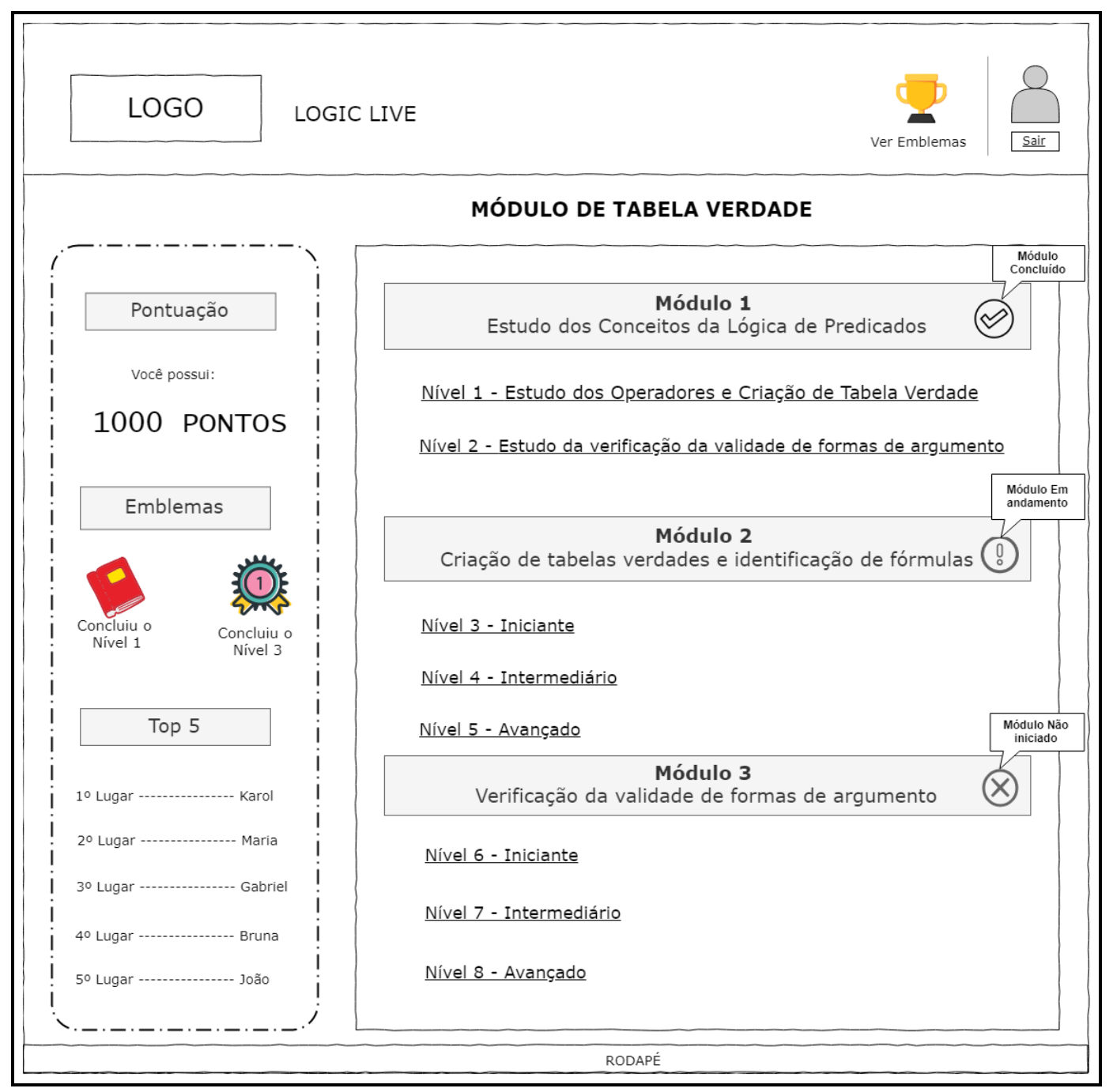

Figura 5 - Protótipo da tela inicial do Módulo de Tabela Verdade gamificado

A Figura 5 apresenta o protótipo desenvolvido para representar a tela inicial do Módulo de Tabela Verdade gamificado. Além das informações dos Módulos de conteúdos de estudo e de exercícios, pensou-se em um espaço para apresentar a Pontuação atual do usuário, seguido dos Emblemas conquistados e a apresentação da Tabela de Classificação.

Ainda na tela têm-se a opção de Sair do módulo e um link intitulado "Ver Emblemas" que abrirá uma modal para exibição dos emblemas que os usuários poderão conquistar no Módulo (canto superior direito na Figura 5). Já a Figura 6 a seguir, apresenta o protótipo desenvolvido para representar a tela de realização dos exercício no Módulo de Tabela Verdade gamificado.

Nessa tela, o título do módulo correspondente e a informação do nível do exercício são exibidos. Em seguida, a fórmula respectiva ao exercício é apresentada, juntamente com as perguntas referentes a ela - a quantidade de perguntas e o enunciado serão definidos pelo(a) professor(a) da disciplina -. 


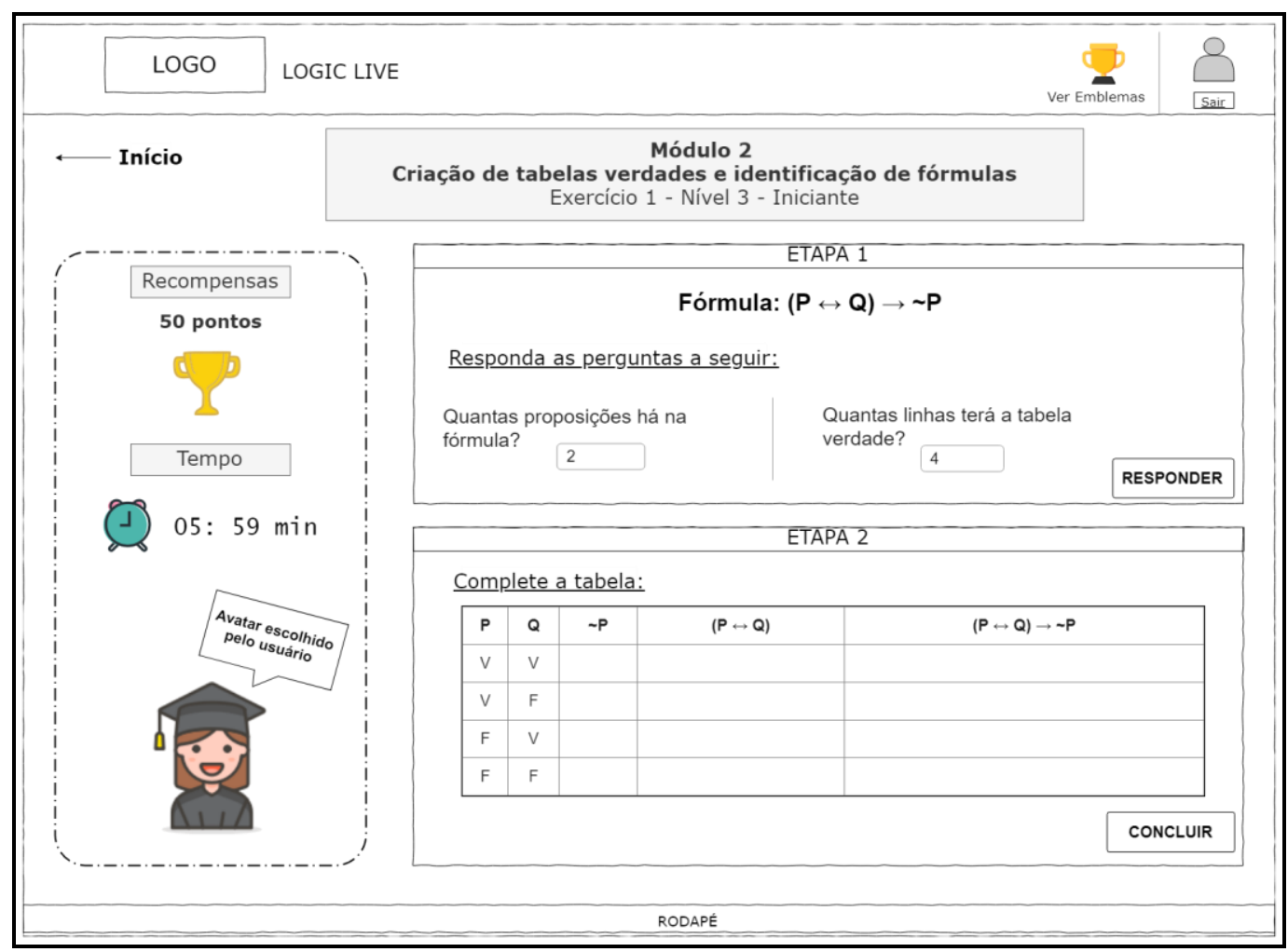

Figura 6 - Protótipo para a tela de resolução de exercícios no Módulo de Tabela Verdade gamificado

A Figura 6 apresenta o protótipo desenvolvido para representar a tela de resolução de exercícios do Módulo de Tabela Verdade gamificado. Como mostra a Figura 6 o exercício é composto por duas etapas, sendo a primeira correspondendo à inserção das respostas das perguntas, e a segunda, o preenchimento da Tabela Verdade para a fórmula apresentada. Além dessas informações, são apresentadas as recompensas que serão obtidas com a conclusão do exercício, o tempo decorrido para resolução e o Avatar definido pelo usuário.

\section{Considerações Finais}

O Módulo de Tabela Verdade tinha a funcionalidade de verificação da tabela verdade correspondente para uma fórmula da Lógica Proposicional, como também a apresentação dos cálculos de valores-verdade das sub-fórmulas e o resultado das verificações da fórmula ao final. Com a gamificação, foram acrescidos conteúdos de estudos e funcionalidades para resolução de exercícios, que envolvem a construção das tabelas-verdade das fórmulas correspondentes, sendo estes interligados aos elementos de jogos.

Sabendo que a motivação através da gamificação pode eventualmente modificar algum comportamento e gerar hábitos entre os usuários, além de estimulá-los ao engajamento das atividades propostas no Módulo, têm-se como trabalho futuro, a implementação da nova estrutura do Módulo de Tabela Verdade. Com isso, uma possível avaliação do Módulo pode ser realizada, ao ser utilizado por um grupo de acadêmicos será possível verificar se a gamificação proposta foi capaz de influenciar no desempenho ou no engajamento desses alunos.

\section{Referências}

Azarite, Ricardo. Gamification: como gerar engajamento com jogos nas redes sociais. 2013. Disponível em: <http://ideas.scup.com/pt/files/downloads/2013/05/gamif ication_scupideas.pdf $>$.Acesso em: 15 set. 2018. 
Bunchball, Gamification. 101: An Introduction to the Use of Game Dynamics to Influence Behavior, 2010. Disponível em: <http:/www. bunchball.com/sites/default/files/ downloads/gamification101.pdf $>$. Acesso em: 22 set. 2018.

Deterding, Sebastian et al. Gamification. using game-design elements in non-gaming contexts. Proceedings Of The 2011 Annual Conference Extended Abstracts On Human Factors In Computing Systems - Chi Ea '11, [s.1.], p.2425-2428, maio 2011. ACM Press. http://dx.doi.org/10.1145/1979742.1979575.

Gomes, Fernanda Pereira; Brito, Parcilene Fernandes de. Módulo de Tabela Verdade para a plataforma online de ensino e aprendizagem de lógica - Logic Live. In: XVIII Jornada de Iniciação Científica, 2018, Palmas. Anais. 2018. Disponível em: <http://ulbrato.br/jornada/wp-content/uploads/2018/10/modulo-de-tabela-verdade-para-a-plataformaonline-de-ensino-e-aprendizagem-de-logica--logic-live.pdf> . Acesso em: 19 abr. 2019.

Hagglund, Per. Taking gamification to the next level: A detailed overview of the past, the present and a possible future of gamification. 2012. 36 f. Umeå Universitet, Suécia, 2012. Disponível em: $\quad<$ http://www.diva-portal.org/smash/get/diva2:5 46713/FULLTEXT01.pdf>. Acesso em: 22 set. 2018.

Medeiros, Diego Marques da Silva; Haydu, Verônica Bender. TICs e a função da gamificação na Educação em Ciências a partir de uma visão analítico- comportamental. X Encontro Nacional de Pesquisa em Educação em Ciências, Águas de Lindóia, p.1-8, nov. 2015. Disponível em: <https://www.researchgate.net/profile/Veronica_Haydu/publication/ 301296890>. Acesso em: 20 out. 2018.

Menezes, Graciela Sardo et al. Reforço e Recompensa: a Gamificação tratada sob uma abordagem behaviorista. Projetica. Londrina, p. 09-18. 18 dez. 2014. Disponível em: $<$ http://www.uel.br/revistas/uel/index.php/projetica/article/viewFile/17746/16089>. Acesso em: 16 set. 2018 .

Oliveira, Thâmillys Marques de; Monteiro, Willmara Marques. Experiências com Gamificação no Ensino de Computação para Jovens e Adultos no Sertão Pernambucano. In: XV Simpósio Brasileiro de Jogos e Entretenimento Digital, 15., 2016, São Paulo. Proceedings of SBGames 2016. p. 914 - 919. Disponível em: $<$ http://www.sbgames.org/sbgames2016/downloads/anais/157340.pdf >. Acesso em: 20 set. 2018.

Vianna, Ysmar et al. Gamification, Inc.: como reinventar empresas a partir de jogos. Rio de Janeiro: Mjv Press, 2013. 116 p.

Werbach, Kevin. Hunter, Dan. For the Win: How Game Thinking Can Revolutionize Your Business. Philadelphia. Wharton Digital Press. 2012, 144p. 